\title{
Classification of Proteus penneri lipopolysaccharides into core region serotypes
}

\author{
Agata Palusiak ${ }^{1}$
}

Received: 29 April 2016 / Accepted: 12 July 2016 / Published online: 28 July 2016

(C) The Author(s) 2016. This article is published with open access at Springerlink.com

\begin{abstract}
The frequency of $P$. penneri isolation from hospital patients, mostly from urine and wounds, keeps on growing, and numerous isolates are multi-drug resistant. $P$. penneri rods produce lipopolysaccharide (LPS), which may lead to the septic shock. Until now, O-specific polysaccharide has been the best structurally and serologically characterized region of $P$. penneri LPS. It is worth having an insight into the serological specificity of both poly- and oligosaccharide parts of $P$. penneri LPS. The $P$. penneri core region is less structurally diverse than OPS, but still, among other enterobacterial LPS core regions, it is characterized by structural variability. In the present study, the serological reactivity of 25 P. penneri LPS core regions was analyzed by ELISA, passive immunohemolysis and Western blot technique using five polyclonal $P$. penneri antisera after or without their adsorption with the respective LPSs. The results allowed the assignment of the tested strains to five new core serotypes, which together with published serological studies led to the creation of the first serotyping scheme based on LPS core reactivities of 35 P. penneri and three $P$. mirabilis strains. Together with the $\mathrm{O}$ types scheme, it will facilitate assigning Proteus LPSs of clinical isolates into appropriate $\mathrm{O}$ and $\mathrm{R}$ serotypes.
\end{abstract}

Keywords Classification scheme $\cdot$ Core region · Core serotype $\cdot$ Lipopolysaccharide $\cdot$ Proteus penneri

Agata Palusiak

agatapal@biol.uni.lodz.pl

1 Department of General Microbiology, Institute of Microbiology, Biotechnology and Immunology, University of Łódź, Banacha 12/16, 90-237 Lodz, Poland

\author{
Abbreviations \\ ELISA Enzyme-linked immunosorbent assay \\ LPS Lipopolysaccharide \\ OPS O-specific polysaccharide \\ OS Oligosaccharide \\ PBS Phosphate-buffered saline \\ PIH Passive immunohemolysis \\ SDS-PAGE Sodium dodecyl sulfate-polyacrylamide gel \\ electrophoresis \\ SRBCs Sheep red blood cells
}

\section{Introduction}

Proteus penneri, previously designated as $P$. vulgaris biogroup 1, was identified and named in 1982 by Hickman et al. [1] on the basis of low DNA relatedness to DNA of the biogroups 2 and 3 representatives and its phenotypic differences. Although these Gram-negative, peritrichously flagellated rods are less common among Proteus spp. clinical isolates than P. mirabilis strains (70-90\% of Proteus spp. infections) [2, 3], the frequency of their isolation from hospital patients keeps on growing [2, 4] and misidentification may further contribute to a lowered number of $P$. penneri isolation reports [3,5]. The most common body sites of $P$. penneri strains isolation are wounds (of abdomen, foot, groin, hip and neck) and the urinary tract, especially of long-term catheterized patients or individuals with anatomical abnormalities within the tract $[2,4,6$, 7]. P. penneri strains were also isolated from: blood, fecal specimens, ankle ulcer, sacral decubitus, conjunctiva, subcutaneous thigh or cerebral abscess, skin lesion aspirate, abdominal drain fluid, diabetic foot ulcer, bronchoalveolar lavage fluid, a pulmonary artery catheter tip, cerebrospinal 
fluid, sputum and the center of struvite bladder stone [2-4, 6, 7].

P. penneri produce many virulence factors which enable them to cause infections, e.g., urease, fimbriae and hemagglutinins, hemolysins, metalloproteases, flagella, siderophores and lipopolysaccharide (LPS) [2, 4]. LPS consists of three structurally different regions: lipid A (defined structurally only for one $P$. mirabilis mutant), core oligosaccharide (OS) and O-specific polysaccharide (OPS) [4, 8]. Until now, OPS has been the best structurally and serologically characterized region of $P$. penneri LPS, which also defines the serospecificity of smooth bacterial cells. Twenty-six different OPS structures have been identified for $P$. penneri strains so far, among which seven are common also to the other representatives of the genus $[4,9,10]$. The $P$. penneri core region is less structurally diverse than OPS but in contrast to other enterobacterial LPS core regions characterized by lager structural variability. Up to date, 12 different structures of the outer core region, accounting for the structural diversity of the P. penneri LPS core regions, were identified (Fig. 1) $[4,11]$. The majority of tested $P$. penneri strains presented one major glycoform of the inner core region $[11,12]$ (Fig. 1). There are only two strains, $P$. penneri 12 and 42, which present glycoforms of the inner core region not identified in any other Proteus spp. LPSs $[4,11,12]$. Moreover, the heterogeneity of this LPS part may appear also within one strain, e.g., P. penneri 13 forms ten variants of its core-lipid A backbone [4]. The P. penneri classification scheme is based on the OPSs serospecificity. So far, P. penneri isolates have been classified into 17 Proteus $\mathrm{O}$ serogroups, among which 13 consist of these species representatives only $[4,9,10,13]$. To have an insight into the serological specificity of both polysaccharide and oligosaccharide parts of $P$. penneri LPS, it is worth creating an additional scheme classifying $P$. penneri LPSs into serotypes of their core regions. A core types classification scheme which together with the O-types scheme may serve as a diagnostic tool facilitating the assignment of Proteus LPSs of clinical isolates into appropriate $\mathrm{O}$ and $\mathrm{R}$ serotypes. In the current work, the results of serological studies prove the existence of another five serotypes of $P$. penneri core regions, which is evidence of further structural variations within this part of Proteus spp. LPS.

\section{Materials and methods}

\section{Bacterial strains and LPSs}

P. penneri 2 (O66), 11, 12 (O58), 16, 18 (O17), 17 (O8), 19, 24 (O64a,b,c), 28 (O31a,b), 31 (O19a,b), 35, 36 and 38 (O64a,b,c) were kindly provided by Prof. D. J. Brenner, Center for Disease Control and Prevention in Atlanta
(USA); P. penneri 100 (O64a,b,c), P. penneri 103 (O73a,b), 107 (O8), 114 (O64a,b,c), 115 (O58) and 124 (R form) were from Dr. B. Holmes (National Collection of Type Cultures, London, UK); and P. penneri 60 (O70), 63 (O68) and $75(\mathrm{O} 73 \mathrm{a}, \mathrm{c})$ were isolated from the urine of patients with bacteriuria in a Łódź hospital. All strains are stored in glycerol at $-80^{\circ} \mathrm{C}$ at the Department of General Microbiology, University of Łódź.

The $P$. penneri 18 LPS was isolated by the phenol-water procedure according to the Westphal and Jann method (1965) and purified with aqueous $50 \%$ trichloroacetic acid [14].

P. penneri $2,11,12,16,17,19,24,26,28,31,35,36$, $38,60,63,75,100,103,107,112,114,115$ and $P$. vulgaris $55 / 57$ LPSs have been previously obtained by the Westphal and Jann method [14], and P. penneri 13 and 124 LPSs, by the phenol/chloroform/petroleum ether method of Galanos (1969) [15]. These LPSs were from the collection of the Department of General Microbiology.

Alkali-treated LPSs used for passive immunohemolysis (PIH) were obtained by LPS saponification with $0.25 \mathrm{M}$ $\mathrm{NaOH}\left(2 \mathrm{~h}, 56{ }^{\circ} \mathrm{C}\right)$ and precipitation with $96 \%$ ethanol [16].

\section{The sera}

Rabbit polyclonal sera against the whole cells of $P$. penneri $17,28,60,103$ and 124 came from the collection of the Department of General Microbiology.

\section{Serological assays}

LPSs samples were checked with the appropriate antiserum in the enzyme-linked immunosorbent assay (ELISA), in Western blot after sodium dodecyl sulfate-polyacrylamide gel electrophoresis (SDS-PAGE) and/or in PIH according to the previously described procedures $[17,18]$. For PIH, sheep red blood cells (SRBCs) were sensitized with alkalitreated LPSs (64-200 $\mu \mathrm{g} / 0.2 \mathrm{ml}$ of SRBCs); $50 \mathrm{ng}$ of LPS per well was used for coating microtiter plates in ELISA. The highest dilution of antiserum giving optical density $405=0.2$ was assumed as the antibodies titer.

\section{Adsorption procedures}

- By alkali-treated LPSs

Single antiserum diluted 1:50 with a veronal buffer $(\mathrm{pH}$ 7.3) was incubated for $30 \mathrm{~min}$ on ice with SRBCs $(0.2 \mathrm{ml})$ sensitized with $200 \mu \mathrm{g}$ of appropriate alkali-treated LPS from one Proteus spp. strain. The antiserum titer was determined by PIH as the last antiserum dilution resulting in $50 \%$ hemolysis [16].

- By the LPS on bacterial cells 


\section{Structures of the core region of $P$. penneri LPSs}

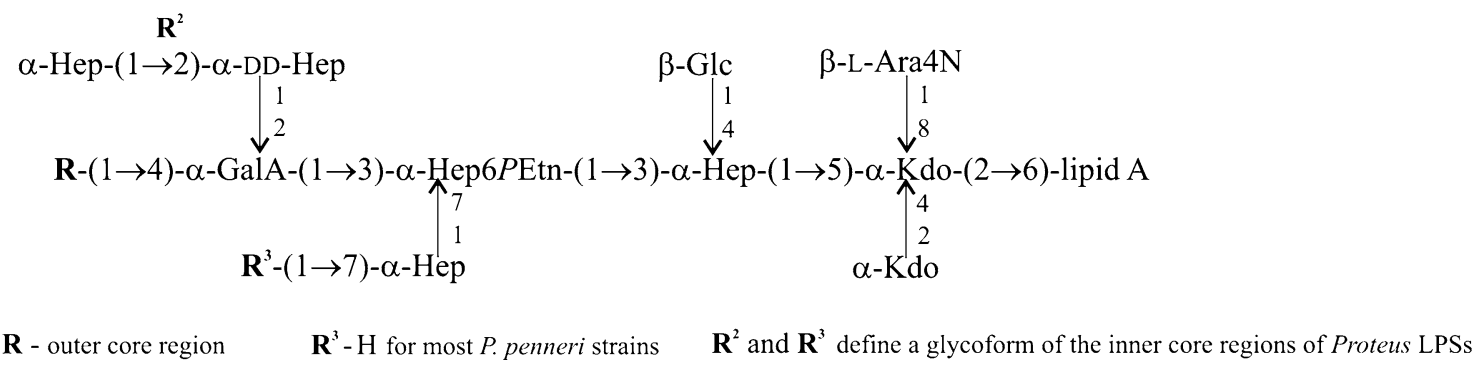

P. penneri 7, 14, 21 and 15 (without Gly residue)

R - $\alpha$-Glc-( $(1 \rightarrow 4)-\alpha$-GalNAc-( $(\rightarrow 2)-\alpha$-DD-Hep-( $1 \rightarrow 6)-\alpha$-GlcNGly

\section{P. penneri 8}

$\mathbf{R}$ - $\alpha$-GalNAc-( $(1 \rightarrow 2)-\alpha$-DD-Hep-( $1 \rightarrow 6)-\alpha$-GlcNGly

\section{P. penneri 42}

$\mathbf{R}$ - $\beta$-GalALys $4 P$ Etn-( $(1 \rightarrow 3)-\beta$-GlcNAc- $(1 \rightarrow 6)-\alpha$-GlcNGly $\mathbf{R}^{2}$ - H

\section{P. penneri 13}

$\mathbf{R}-\alpha$-GalN $\quad \mathbf{R}^{2}-\alpha$-Hep-(1 $\left.\rightarrow 2\right)-\alpha$-DD-Hep or $\mathrm{H} \quad \mathbf{R}^{3}-\mathrm{H}$ or $\beta$-GalAN

\section{P. penneri 26}

R - $\beta$-Glc- $(1 \rightarrow 3)-\alpha-$ GalN

\section{P. penneri 12}

$\mathbf{R}$ - $\alpha$-GalN $\quad \mathbf{R}^{2}$ - $\alpha$-DD-Hep

\section{P. penneri 37, 44}

$\mathbf{R}-\beta$-GlcNAc- $(1 \rightarrow 4)-\alpha$-GlcN $\mathbf{R}^{3}-\mathrm{H}$ or $\beta$-GalAN

\section{P. penneri 25}

R - $\alpha$-Gal- $(1 \rightarrow 3)-\beta$-GlcNAc- $(1 \rightarrow 4)-\alpha-$-GlcN6PEtn

\section{P. penneri 17, 2, 11, 19, 107}

R - $\beta$-Gal- $(1 \rightarrow 4)-(1 S)$-GaloNAc- $(1 \rightarrow 4,6)-\alpha$-GalN

\section{P. penneri 16, 18}

R - $\alpha$-Fuc3NHb-( $(1 \rightarrow 4)-\alpha-G a l-(1 \rightarrow 6)-\beta$-Glc- $(1 \rightarrow 3)-\alpha-$ GalN6PEtn

\section{P. penneri 40}

$\mathbf{R}$ - $\alpha$-Glc- $(1 \rightarrow 6)-\beta$-Gal-( $(1 \rightarrow 4)-(1 S)-$ GaloNAc- $(1 \rightarrow 4,6)-\alpha-$ GalN

\section{P. penneri 103}

R - $\beta$-Glc-( $1 \rightarrow 4)-\alpha-$-GlcNAc- $(1 \rightarrow 4)-\alpha-$-GalN6Ac

Fig. 1 Structural variability of $P$. penneri LPS core regions [11]; Arap4N, 4-amino-4-deoxy-L-arabinopyranose; Fuc3NHb, 3-[(R)3-hydroxybutyryl]amino-3,6-dideoxy-D-galactose, Gal, galactose; GalA, galacturonic acid; GalALys, amide of GalA with lysine; GalAN, amide of GalA with aliphatic polyamines; GalN, galactosamine; GalNAc, 2-acetamido-2-deoxy-D-galactose; (1S)-GaloNAc, open-chain form of GalNAc; GalN6Ac, 6- $O$-acetyl-2-amino-2-deoxy-D-galactose; Glc, glucose; GlcNAc, 2-acetamido-2-deoxyD-glucose; GlcNGly, 2-glycylamino-2-deoxy-D-glucose; Hep, L-glycero-D-manno-heptose; DD-Hep, D-glycero-D-manno-heptose; Kdo, 3-deoxy-D-manno-oct-2-ulosonic acid; and PEtn, 2-aminoethyl phosphate 
This adsorption procedure was performed in the case of i.a. the P. penneri 17 antiserum due to the weak activity of cross-reacting alkali-treated LPSs in PIH compared to activity of the native LPSs in ELISA.

A wet mass of bacterial cells, after being washed in phosphate-buffered saline (PBS), was suspended in serum diluted 1:100 in PBS, incubated for $30 \mathrm{~min}$ on ice and removed from the serum by centrifugation.

Each serum was adsorbed three-four times to make sure that all antibodies that were able to bind to LPS molecules were removed from the serum.

\section{Results}

In previous serological studies, sera specific to appropriate P. penneri strains were tested with a set of 40 P. penneri LPSs and the core region serospecificity for the majority of those antigens was determined [16, 17, 19, 20]. In the present work, the reactivities of the core regions of $P$. penneri LPSs $2,11,12,13,16,17,18,19,24,26,28,31,35$, $36,38,60,63,75,100,103,107,112,114,115$ and 124 with five sera specific to the strains $P$. penneri 17,103 (with defined structures of LPS core regions [11]), 28, 60 and 124 were analyzed by ELISA and Western blot and classified into core serotypes. Each serum was adsorbed with a single cross-reacting antigen and tested again in PIH or in ELISA ( $P$. penneri 17 antiserum) with all LPSs reacting with the serum to exclude further serological differences within the groups.

\section{P. penneri 28 antiserum}

P. penneri 28 antiserum has been obtained by immunizing with whole bacterial cells. O-polysaccharide-specific immunoglobulins were eliminated from the serum by its adsorption with an alkali-treated LPS of $P$. vulgaris $55 / 57$ $(\mathrm{O} 31 \mathrm{a}, \mathrm{b})$ containing the OPS structurally identical to $P$. penneri 28 OPS and a different core region serotype [21]. A lack of reaction with $P$. vulgaris 55/57 LPS indicated that all antibodies specific to the OPS were completely removed from the serum (Fig. 2a). This antiserum will be referred to as anti-core serum. Three LPSs, P. penneri 16, 18 and 31, reacted with this serum in ELISA of which $P$. penneri 31 was distinguished by the lowest reactivity titer (Table 1 ). In Western blot, P. penneri 28 anti-core serum bound to lowmolecular-mass LPS species (consisting of the core-lipid A moieties) of all the LPSs used, among which P. penneri 18 LPS showed the strongest and the most distinguishing reactions (Fig. 2a). The ladder-like banding pattern, which can be noticed in Fig. 2a, also corresponds to the low-molecular-mass LPS species of $P$. penneri 18 LPS. This observation was confirmed by the Western blot results obtained for P. penneri 18 LPS and antiserum against the P. penneri 28 strain after its adsorption with $P$. penneri 18 LPS molecules. The reactions previously observed in Western blot with unadsorbed anti-core serum (Fig. 2a), were abolished. Moreover, P. penneri 28 anti-core serum adsorbed with $P$. penneri 16, 18 and 31 LPSs did not react in PIH with any of the antigens used (data not showed).

\section{P. penneri 17 antiserum}

Although P. penneri 17 antiserum is specific to the whole bacterial strains, P. penneri 17 LPS did not show in Western blot (Fig. 2b,c) the reaction typical for the highmolecular-mass LPS species containing O-polysaccharide, which suggests that core-specific antibodies dominate in the serum. In ELISA, the P. penneri 17 antiserum strongly cross-reacted with $P$. penneri 2, 11, 19 and 107 LPSs (Table 1), which is in accordance with structural studies which showed that all LPSs present one structural type of the core region (Fig. 1) [11]. Further, six LPSs from $P$. penneri 24, 35, 36, 38, 100, and 114 exhibited in ELISA strong cross-reactions, whereas P. penneri 115 LPS showed only weak reactivity (Table 1 ). In Western blot, the reactions of $P$. penneri 17 antiserum, concerning the core-lipid A molecules of all used $P$. penneri LPSs, were similar to the reaction of homologous LPS (Fig. 2b, c). The adsorption of the P. penneri 17 antiserum by each tested antigen completely abolished its reactivity with all the LPSs used (data not showed).

\section{P. penneri 60 antiserum}

In ELISA, anti-P. penneri 60 serum cross-reacted with one LPS, P. penneri 63 , but more weakly than homologous LPS (Table 1). In Western blot, P. penneri 60 recognized only fast migrating bands of $P$. penneri 63 LPS (Fig. 2d), which explains the weak reaction observed for this system in ELISA (Table 1). After the adsorption of P. penneri 60 antiserum by $P$. penneri 63 LPS, the titer of its reactivity with homologous LPS was slightly lower compared to the titer of non-adsorbed serum (Fig. 3a). In order to find out which part of LPS was recognized by the antibodies that remained in the adsorbed serum, the serum was checked with both tested LPSs in Western blotting (Fig. 3a). As expected, the adsorption procedure removed the anti-core-specific antibodies from the serum, which indicates that $P$. penneri 60 and 63 LPSs present one serotype of the core regions.

\section{P. penneri 103 antiserum}

P. penneri 103 antiserum cross-reacted in ELISA only with one LPS and P. penneri 75 to the titer equal to that of homologous LPS (Table 1). In Western blot, similar strong 
Fig. 2 Western blot data of Proteus spp. LPSs with antisera against: a $P$. penneri 28 (anticore serum), b, c $P$. penneri 17 , d $P$. penneri 60 , e $P$. penneri 103 and $\mathbf{f}$ P. penneri 124 a

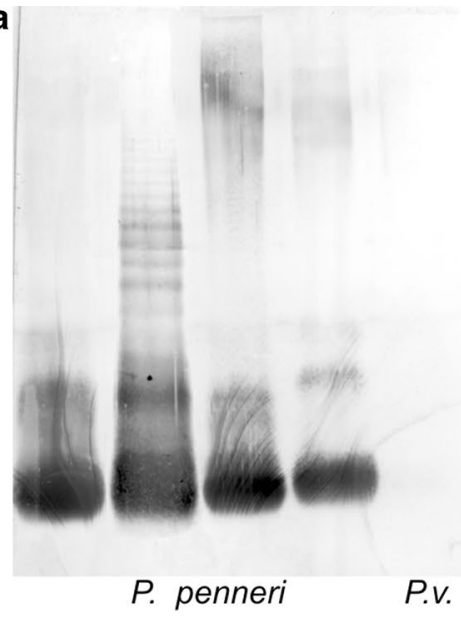

$\begin{array}{lllll}31 & 18 & 16 & 28 & 55 / 57\end{array}$

C b

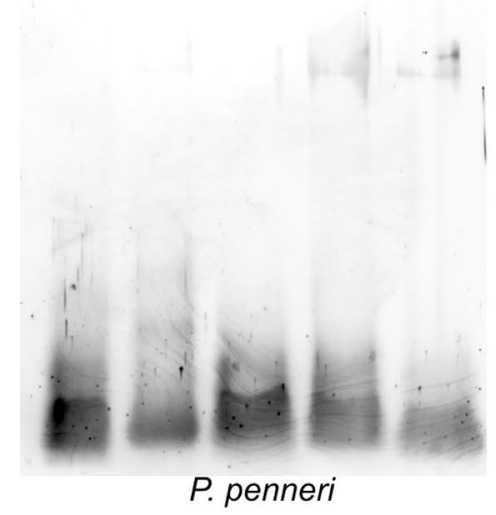

$\begin{array}{lllll}17 & 2 & 11 & 19 & 107\end{array}$

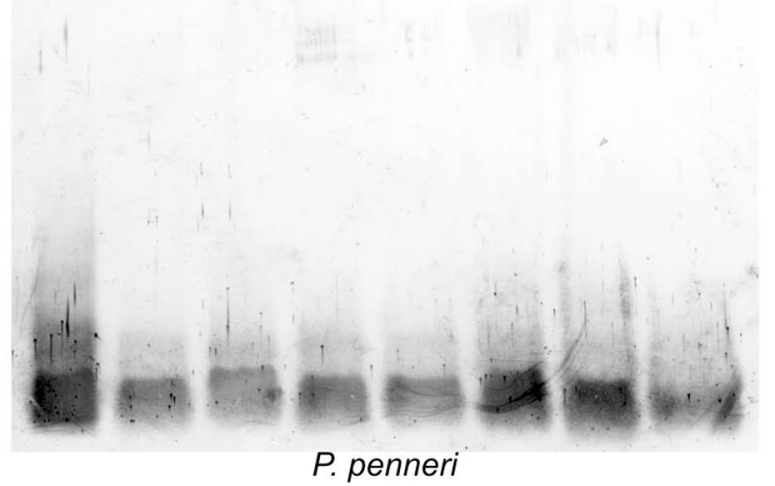

P. penneri d

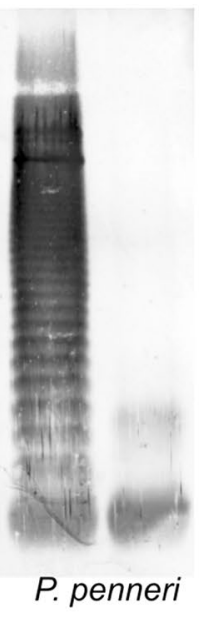

60

63

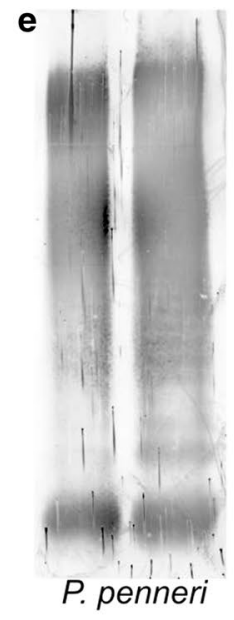

75103 $\begin{array}{llllll}35 & 36 & 38 & 100 & 114 & 115\end{array}$

\section{f}

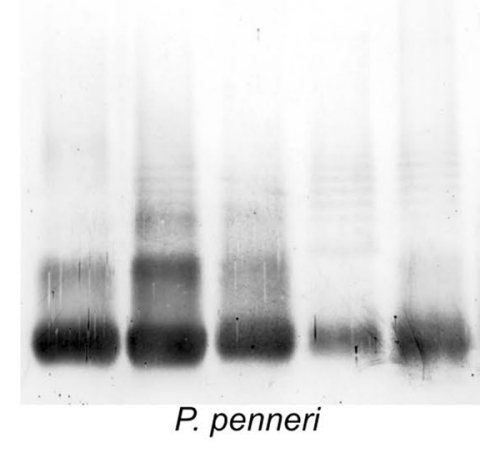

$\begin{array}{lllll}124 & 12 & 13 & 112 & 26\end{array}$ 
Table 1 Reactivity of $P$. penneri 28 anti-core serum and antisera against $P$. penneri 17, 60, 103 and 124 with the $P$. penneri LPSs in ELISA $^{\mathrm{a}}$

\begin{tabular}{lr}
\hline LPSs from $P$. penneri strains & Reciprocal titer for LPS in ELISA \\
\hline P. penneri 28 anti-core serum & \\
P. penneri 28 & 128.000 \\
P. penneri 16 & 64.000 \\
P. penneri 18 & 128.000 \\
P. penneri 31 & 32.000 \\
P. penneri 17 antiserum & \\
P. penneri 17 & 64.000 \\
P. penneri 2 & 16.000 \\
P. penneri 11 & 64.000 \\
P. penneri 19 & 32.000 \\
P. penneri 107 & 16.000 \\
P. penneri 24 & 16.000 \\
P. penneri 35 & 32.000 \\
P. penneri 36 & 16.000 \\
P. penneri 38 & 16.000 \\
P. penneri 100 & 16.000 \\
P. penneri 114 & 16.000 \\
P. penneri 115 & 8.000 \\
P. penneri 60 antiserum & \\
P. penneri 60 & 512.000 \\
P. penneri 63 & 4.000 \\
P. penneri 103 antiserum & \\
P. penneri 103 & 1024.000 \\
P. penneri 75 & 1024.000 \\
P. penneri 124 antiserum & \\
P. penneri 124 & 32.000 \\
P. penneri 12 & 32.000 \\
P. penneri 13 & \\
P. penneri 112 & \\
P. penneri 26 & \\
\hline & \\
\hline & \\
\hline
\end{tabular}

${ }^{\text {a }}$ Data for the homologous LPSs are italicized

reactions were observed for the serum with both high- and low-molecular-mass LPS species of the homologous strain and of the cross-reacting P. penneri 75 strain (Fig. 2e). After the adsorption of $P$. penneri 103 antiserum by P. penneri 75 LPS, only a small fraction of anti-LPS antibodies, reacting to the titer 1:400 in PIH and recognizing slowmigrating bands of P. penneri 103 LPS in Western blotting, remained in the serum (Fig. 3b).

\section{P. penneri 124 antiserum}

P. penneri 124 antiserum is specific to the clinical rough strain, i.e., it contains the core-specific antibodies only. It was selected for the studies to check whether $P$. penneri 124 LPS presents the same core region serotype as the type strain of the species, P. penneri 12 (American Type Culture Collection 33519) with the known core region structure (Fig. 4) [11]. The previous serological studies conducted with the use of the $P$. penneri 13 antiserum showed its strong cross-reactivity with P. penneri 12, 124, 26 and 112 LPSs, reacting to the same reactivity titer $(1: 16.000)$ as $P$. penneri 13 LPS [16]. To confirm the previously obtained results, the P. penneri 13, 26 and 112 LPSs were additionally selected to be included in the present work. As was expected, the $P$. penneri 124 antiserum reacted in ELISA identically with $P$. penneri $12,124,13$ and 112 LPSs, but the reaction with $P$. penneri 26 LPS was characterized by the lowest intensity (Table 1). In Western blot, the P. penneri 124 antiserum recognized the fast migrating bands of all tested LPSs (Fig. 2f). In contrast to ELISA results, $P$. penneri 112 LPS reacted more weakly than homologous LPS. The adsorption procedure of the tested serum completely abolished all reactions previously observed for nonadsorbed serum (data not showed).

\section{Discussion}

The serological results of the present study have allowed classifying 22 LPSs of P. penneri 2, 11, 12, 16, 17, 18, 19, $24,28,31,35,36,38,60,63,75,100,103,107,114,115$ and 124 into one of the five new core serotypes (Table 2, below the middle line). Four of the antigen groups contain LPSs with determined core region structures [11] (in Table 2 marked with*), and one contains only LPSs ( $P$. penneri 60 and 63) with structurally unknown core regions. Table 2 includes all serotypes of LPS core regions formed on the basis of the results (Table 1; Figs. 2,3) and previous serological studies $[16,17,19,20]$. The studies were possible to perform owing to a unique set of anti-core sera obtained by: (1) the adsorption of serum against the bacterial whole cells by the LPS possessing the same O-polysaccharide as the strain homologous to the serum and different core region serotypes, (2) the immunization of rabbit with the conjugate of core oligosaccharide with diphtheria toxoid and (3) the immunization of rabbit with the whole cells of rough strains or of smooth strains but having the majority of LPS molecules unsubstituted with O-polysaccharide chains.

Assigning the $P$. penneri LPSs to the appropriate core serotype has not always been easy to perform. In some cases, one LPS cross-reacted with the appropriate serum similarly to homologous LPS in one method and weaker in another technique, e.g., $P$. penneri 112 LPS reacted with $P$. penneri 124 antiserum to the same titer as homologous LPS (Table 1) and in Western blot more weakly than homologous LPS (Fig. 2f). The differences in the antisera reactivity titers within one group of LPSs may also result from the 
Fig. 3 Passive immunohemolysis and Western blot data of the $P$. penneri LPSs with adsorbed antisera against strains: a $P$. penneri 60, b $P$. penneri 103 . The data in frames show the reactions of antibodies remaining in the tested serum after its adsorption by: a P. penneri 63 LPS molecules, b P. penneri 75 LPS molecules a

Alkali-treated Reciprocal titer of adsorbed or non-adsorbed

LPS used for the (control) antiserum for P. penneri LPSs

adsorption 63

P. penneri 60 anti-serum

Control 60

\section{P. penneri 60}

P. penneri 63

51.200

$<100$

25.600

12.800

$<100$

$<100$

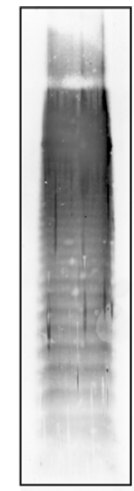

P. penneri

60

b

\begin{tabular}{lrc}
\hline $\begin{array}{l}\text { Alkali-treated } \\
\text { LPS used for the } \\
\text { adsorption }\end{array}$ & \multicolumn{2}{c}{$\begin{array}{l}\text { Reciprocal titer of adsorbed or non-adsorbed } \\
\text { (control) antiserum for } P \text {. penneri LPSs }\end{array}$} \\
\cline { 2 - 3 } P. penneri 103 & anti-serum & 75 \\
Control & 103 & \\
P. penneri 103 & 12.800 & 6.400 \\
P. penneri 75 & $<100$ & $<100$ \\
& 400 & $<100$
\end{tabular}

Fig. 4 LPS core region structures of: a $P$. penneri $12, \mathbf{b} P$. penneri 13 and $\mathbf{c}$ P. penneri 26 LPSs [11, 16]; Arap4N, 4-amino-4-deoxy-L-arabinopyranose; GalA, galacturonic acid; GalN, galactosamine; Glc, glucose; DD-Hep, D-glyceroD-manno-heptose; Kdo, 3-deoxy-D-manno-oct-2-ulosonic acid; and $P$ Etn, 2-aminoethyl phosphate a

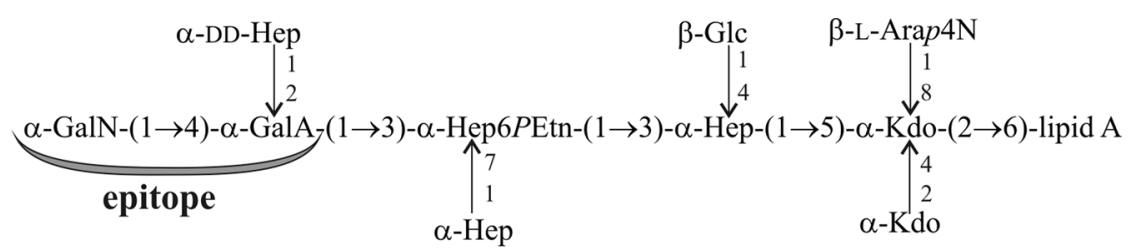

b
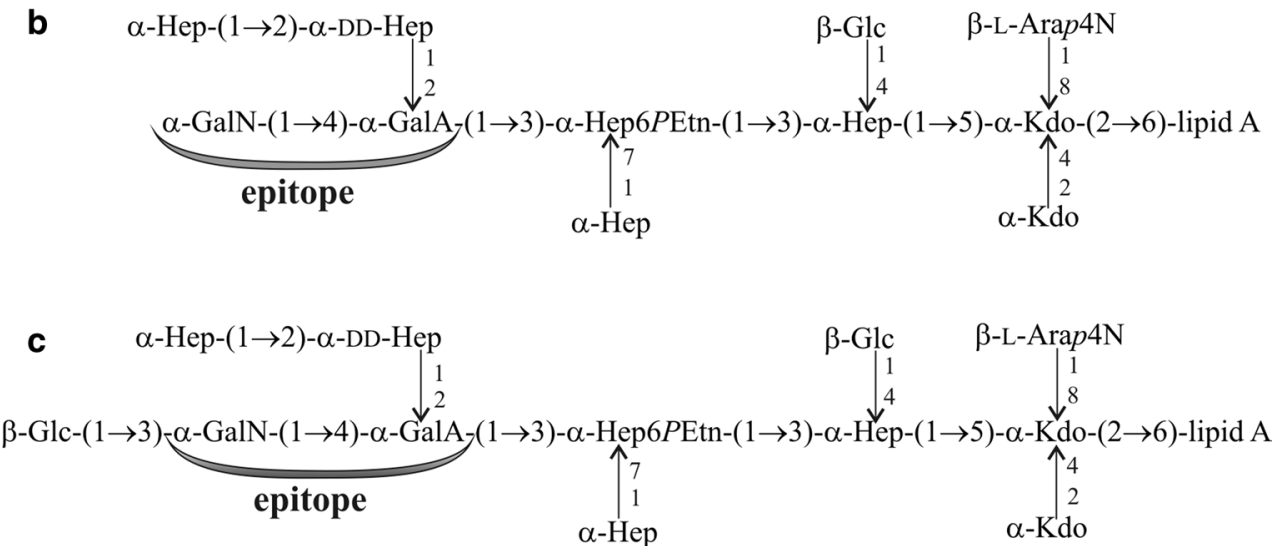
Table 2 First typing scheme based on the core region serological specificity of 35 P. penneri and three P. mirabilis LPSs

\begin{tabular}{|c|c|c|}
\hline No. & The core serotype presented by the LPSs & Other representatives of core region serotypes \\
\hline 1. & P. penneri $7 *(\mathrm{O} 61)$ & P. penneri $14 *(\mathrm{O} 59)$ and $15^{*}(\mathrm{O} 52)$ \\
\hline 2. & P. penneri $8^{*}(\mathrm{O} 67)$ & P. penneri $34(\mathrm{O} 65)$ and $133(\mathrm{O} 61)$ \\
\hline 3. & P. penneri $42 *(\mathrm{O} 71)$ & P. mirabilis 51/57* (O28) and R14/S1959 \\
\hline 4. & P. penneri $13^{*}$ (rough form) & P. penneri $112(\mathrm{O} 8)$ \\
\hline 4a. & Subgroup & P. penneri $26^{*}(\mathrm{O} 31 \mathrm{a})$ \\
\hline 5. & P. penneri $37 *$ (rough form) & P. penneri $44^{*}$ (rough form) \\
\hline 6. & P. mirabilis $\mathrm{R} 110 *$ (rough mutant) & P. penneri 47 (O59) \\
\hline 7. & P. penneri $28(\mathrm{O} 31 \mathrm{a}, \mathrm{b})$ & P. penneri $16^{*}, 18^{*}(\mathrm{O} 17)$ and $31(\mathrm{O} 19 \mathrm{a}, \mathrm{b})$ \\
\hline 8. & P. penneri $17 *(\mathrm{O} 8)$ & $\begin{array}{l}\text { P. penneri } 2 *(\mathrm{O} 66), 11^{*}(\mathrm{O} 58), 19^{*}, 24,35,36,38, \\
100,114(\mathrm{O} 64 \mathrm{a}, \mathrm{b}, \mathrm{c}), 107^{*}(\mathrm{O} 8) \text { and } 115(\mathrm{O} 58)\end{array}$ \\
\hline 9. & P. penneri $60(\mathrm{O} 70)$ & P. penneri 63 (O68) \\
\hline 10. & P. penneri $103 *(\mathrm{O} 73 \mathrm{a}, \mathrm{b})$ & P. penneri $75(\mathrm{O} 73 \mathrm{a}, \mathrm{c})$ \\
\hline 11. & P. penneri 124 (rough form) & P. penneri $12 *(\mathrm{O} 58)$ \\
\hline
\end{tabular}

LPS of the structurally defined core regions

The first representatives of each core region serotype are homologous to the respective antiserum used in the studies

() O serotype of LPS

different number of LPS molecules substituted and unsubstituted with OPS-chains, thus from the different access of antibodies to the core region.

Although P. penneri 28 LPS possesses the core region with an unknown structure, it was selected as a representative of serotype no. 7 (Table 2) because it was possible to obtain the serum specific to its core region. The reactions observed for this serum in Western blot (Fig. 2a) with $P$. penneri 28, 16, 18 and 31 LPSs were the most diverse in their intensity. The LPS exhibiting the most distinguished reaction was $P$. penneri $18 \mathrm{LPS}$, for which the ladder-like banding pattern was observed at the level corresponding to the higher-molecular LPS species. Smearing which appeared for P. penneri 28 and 16 LPSs at the level, typical for higher-molecular mass species, concerned unspecific reactions since both LPSs have no common fragments in the OPS parts [9]. What is more, P. vulgaris 55/57 OPS which is known to be structurally identical to the $\mathrm{O}$-antigen of the P. penneri 28 LPS has not reacted with the tested serum (Fig. 2a). The method, which occurred to be very useful for proving that all tested antigens present a common core region serotype, was the serum adsorption. It allowed abolishing the reactions observed previously with the unadsorbed serum (Table 1; Fig. 2a). The procedure of antiserum adsorption, by LPS molecules coated on SRBC as well as on the bacterial cells, is a proven method for assessing serological similarities between antigens. Even though slight differences in reactivities have been observed for a group of LPSs with unadsorbed serum, the adsorption procedure usually appears to be helpful in explaining disputable results $[16,17]$.
The serum adsorption procedure also enabled classifying 11 LPS to the core serotype presented by P. penneri 17 LPS. It is the most numerous group among the analyzed LPSs, having one serotype of the core region, including five LPSs of the determined core region structures ( $P$. penneri 2,11,17, 19 and 107). The structural studies showed that the core regions of the mentioned LPSs possess a unique type of linkage [(1S)-GaloNAc- $(1 \rightarrow 4,6)-\alpha-\mathrm{GalN}]$ occurring also in OSs of a few Proteus spp. LPSs, which had not previously been reported in natural glycopolymers [11]. This linkage probably occurs in OSs of the remaining $P$. penneri LPS presenting the same serotype as the P. penneri 17 core region.

LPSs $P$. penneri 60 and 63 present a core region serotype new for $P$. penneri strains tested so far $[16,17,19$, 20]. $P$. penneri 60 antiserum cross-reacted only with the low-molecular-mass species of P. penneri 63 (Fig. 2d). This result also stays in agreement with the structural data showing that in OPSs of both LPSs there is no common fragment except for the $N$-acetyl-fucosamine residue [-3)- $\alpha$-LFucpNAc-(1-] [9, 22]. It should be remembered that, in contrast to the anti-core sera, O-specific immunoglobulins predominate in the sera specific to the whole bacterial cells, including $P$. penneri 60 antiserum. It was reflected in ELISA by the higher titer of the serum with homologous LPS than that observed for $P$. penneri 63 LPS (Table 1). $P$. penneri 63 LPS was assigned to the core region serotype presented by P. penneri 60 LPS on the grounds of the Western blot results after the serum adsorption by $P$. penneri 63 LPS molecules (Fig. 3a). Abolishing the bands corresponding to the reactions with low-molecular-mass species of 
both tested LPSs and leaving the ladder-like banding pattern typical for the serum reaction with high-molecularmass species of $P$. penneri 60 LPS (Fig. 3a, in a frame) clearly confirmed the suggestion that these LPSs present a similar serotype of the core region.

P. penneri 103 LPS was found to present the same core region serotype as $P$. penneri 75 LPS on the basis of the Western blot results obtained after the adsorption of $P$. penneri 103 antiserum by $P$. penneri 75 LPS (Fig. 3b). Only a slight reaction with slow-migrating bands of P. penneri 103 LPS was observed. Comparing the OPSs structures of both LPSs, it can be noticed that they differ only in the lateral substituents of the glucose residue and probably the lateral group (Etn $P$ in $P$. penneri 103 OPS) was recognized by the immunoglobulins remaining in anti-P. penneri 103 serum after its adsorption by $P$. penneri 75 LPS (D-Glc residue except $\operatorname{Etn} P$ ) (Fig. 3b, the reaction in a frame) [23].

The $P$. penneri 124 strain possesses LPS with a structurally unidentified core region, but its rough form decided about its selection for the studies. All serological data, the previous [16] and present ones (Table 1; Fig. 2f), indicate the $P$. penneri 124 LPS core region as serologically identical to the OS of $P$. penneri 12 LPS with a known core region structure (Fig. 4). Analyzing the results of P. penneri 124 antiserum and the previous results obtained for $P$. penneri 13 antiserum [16] in relation to the core region structures of P. penneri 12, 13 and 26 LPSs (Fig. 4) [11], it was confirmed that the common fragment of the core regions: $\alpha$-GalN- $(1 \rightarrow 4)-\alpha-G a l A$ may be responsible for the observed cross-reactions. The results obtained for $P$. penneri 124 antiserum, after its adsorption by the tested $P$. penneri LPSs (data not showed), differ insignificantly from those obtained for P. penneri 13 antiserum [16]. Adsorption of $P$. penneri 13 antiserum with $P$. penneri 12 and 124 LPSs left a small fraction of antibodies (reciprocal titer 1.600) reacting with $P$. penneri 13,112 and 26 LPSs, which was not observed in the present studies (all antibodies against P. penneri 12 and 124 LPSs were removed). It had been shown previously that those antibodies probably recognized the $\alpha$-Hep- $(1 \rightarrow 2)-\alpha$-DD-Hep fragment, which is present in the core region of $P$. penneri 13 (probably of 112) and 26 LPSs but absent from $P$. penneri 12 LPS (probably from $P$. penneri 124) (Fig. 4). The weaker reaction of $P$. penneri 124 antiserum with $P$. penneri 26 LPS (Table 1; Fig. 2f) can be explained by: (1) the lack in the serum of the antibodies binding to the heptose disaccharide, (2) the additional terminal Glc residue (present only in the OS of P. penneri 26 LPS), absent from the outer core region of the remaining LPSs tested (Fig. 4), which may hamper binding the antibodies to the $\alpha$-GalN- $(1 \rightarrow 4)-\alpha$-GalA fragment. However, this small structural difference in the $P$. penneri 13 and 26 core regions had not been shown to result in decreasing the titer of $P$. penneri 13 antiserum reactivity with $P$. penneri
26 LPS, compared to the titer in the homologous system [16]. Thus, the P. penneri 26 LPS was classified into the group of LPSs (with one core region serotype) represented by $P$. penneri 13 LPS as its subgroup 4 a (Table 2).

Serological classification of Proteus spp. strains is not a typing method commonly used in clinical laboratories. However, the serological classification scheme based on the $P$. penneri core region provides useful information necessary for assigning the clinical isolates, not only from $P$. penneri species, to an appropriate core region serotype. Further extension of the scheme with other representatives may form a database, which, together with the scheme of Proteus LPS O-types, will show which core region serotype dominates within an area where the tested isolates come from. This may help in the selection of antigens presenting the most common $\mathrm{O}$ and $\mathrm{R}$ serotypes and serve as a tool to identify common epitopes among strains which may upon immunisation lead to the formation of cross-reactive and cross-protective antibodies against the core region as shown in one example for E. coli [24].

Acknowledgments This work was partially supported by the Ministry of Science and Higher Education (Poland), Grant No. N 401001 31/0009.

Open Access This article is distributed under the terms of the Creative Commons Attribution 4.0 International License (http://creativecommons.org/licenses/by/4.0/), which permits unrestricted use, distribution, and reproduction in any medium, provided you give appropriate credit to the original author(s) and the source, provide a link to the Creative Commons license, and indicate if changes were made.

\section{References}

1. Hickman FW, Steigerwalt AG, Farmer JJ III, Brenner DJ (1982) Identification of Proteus penneri sp. nov., formerly known as Proteus vulgaris indole negative or as Proteus vulgaris biogroup 1. J Clin Microbiol 15:1097-1102

2. Drzewiecka D, Sidorczyk Z (2005) Charakterystyka gatunku Proteus penneri-warunkowych patogenów człowieka. Post Mikrobiol 44:113-126

3. Kishore J (2012) Isolation, identification and characterization of Proteus penneri-a missed rare pathogen. Indian J Med Res $135: 341-345$

4. Palusiak A (2013) Immunochemical properties of Proteus penneri lipopolysaccharides-one of the major Proteus sp. virulence factors. Carbohydr Res 380:16-22. doi:10.1016/j. carres.2013.06.025

5. Pandey A, Verma H, Asthana AK, Madan M (2014) Extended spectrum beta lactamase producing Proteus penneri: a rare missed pathogen? Indian J Pathol Microbiol 57:489-491. doi:10.4103/0377-4929.138791

6. Feglo PK, Gbedema SY, Quay SNA, Adu-Sarkodie Y, OpokuOkrah C (2010) Occurrence, species distribution and antibiotic resistance of Proteus isolates: a case study at the Komfo Anokye Teaching Hospital (KATH) in Ghana. Int J Pharm Sci Res $1: 347-352$ 
7. O’Hara CM, Brenner FW, Miller JM (2000) Classification, identification, and clinical significance of Proteus, Providencia, and Morganella. Clin Microbiol Rev 13:534-546

8. Sidorczyk Z, Zähringer U, Rietschel ET (1983) Chemical structure of the lipid A component of the lipopolysaccharide from a Proteus mirabilis Re mutant. Eur J Biochem 137:15-22. doi:10.1111/j.1432-1033.1983.tb07789.x

9. Knirel YA, Perepelov AV, Kondakova AN, Senchenkova SN, Sidorczyk Z, Rozalski A, Kaca W (2011) Structure and serology of O-antigens as the basis for classification of Proteus strains. Innate Immun 17:70-96. doi:10.1177/1753425909360668

10. Siwińska M, Levina EA, Ovchinnikova OG, Drzewiecka D, Shashkov AS, Różalski A, Knirel YA (2015) Classification of a Proteus penneri clinical isolate with a unique $\mathrm{O}$-antigen structure to a new Proteus serogroup, O80. Carbohydr Res 407:131136. doi:10.1016/j.carres.2015.02.003

11. Vinogradov EV, Sidorczyk Z, Knirel YA (2002) Structure of the lipopolysaccharide core region of the bacteria of the genus Proteus. Aust J Chem 55:61-67. doi:10.1071/CH01184

12. Kondakova AN, Vinogradov EV, Knirel YA, Lindner B (2005) Application of electrospray ionization with Fourier transform ion cyclotron resonance mass spectrometry for structural screening of core oligosaccharides from lipopolysaccharides of the bacteria Proteus. Rapid Commun Mass Spectrom 19:2343-2349. doi:10.1002/rcm.2064

13. Palusiak A, Siwińska M, Sidorczyk Z (2013) Serological studies of Proteus penneri strains determining qualification to appropriate O-serogroup. Pol J Microbiol 62:211-216

14. Westphal O, Jann K (1965) Bacterial lipopolysaccharides. Extraction with phenol-water and further applications of the procedure. Methods Carbohydr Chem 5:83-91

15. Galanos C, Lúderitz O, Westphal O (1969) A new method for the extraction of R lipopolysaccharides. Eur J Biochem 9:245-249. doi:10.1111/j.1432-1033.1969.tb00601.x

16. Palusiak A, Sidorczyk Z (2009) Serological characterization of the core region of lipopolysaccharides of rough Proteus sp. strains. Arch Immunol Ther Exp 57:303-310. doi:10.1007/ s00005-009-0034-9

17. Palusiak A, Dzieciątkowska M, Sidorczyk Z (2008) Application of two different kinds of sera against Proteus penneri lipopolysaccharide core region in search of epitopes determining cross-reactions with antibodies. Arch Immunol Ther Exp 56:135-140. doi:10.1007/s00005-008-0012-7

18. Sidorczyk Z, Zych K, Toukach FV, Arbatsky NP, Zabłotni A, Shashkov AS, Knirel YA (2002) Structure of the O-polysaccharide and classification of Proteus mirabilis strain G1 in Proteus serogroup O3. Eur J Biochem 269:1406-1412. doi:10.1046/j.1432-1033.2002.02782.x

19. Palusiak A, Sidorczyk Z (2010) Characterization of epitope specificity of Proteus penneri 7 lipopolysaccharide core region. Acta Biochim Pol 57:529-532

20. Palusiak A, Maciejewska A, Ługowski C, Różalski A (2014) The amide of galacturonic acid with lysine as an immunodominant component of the lipopolysaccharide core region from Proteus penneri 42 strain. Acta Biochim Pol 61:129-132

21. Kondakova AN, Zych K, Senchenkova SN, Bartodziejska B, Shashkov AS, Knirel YA, Rozalski A, Sidorczyk Z (2003) Structure of the O-polysaccharide of Proteus penneri 28 and Proteus vulgaris $\mathrm{O} 31$ and classification of P. penneri 26 and 28 in Proteus serogroup O31. FEMS Immunol Med Microbiol 39:87-93. doi:10.1016/S0928-8244(03)00208-6

22. Zych K, Perepelov AV, Baranowska A, Zabłotni A, Shashkov AS, Knirel YA, Sidorczyk Z (2005) Structure of the O-polysaccharide and serological studies of the lipopolysaccharide of Proteus penneri 60 classified into a new Proteus serogroup O70. FEMS Immunol Med Microbiol 43:351-356. doi:10.1016/j. femsim.2004.09.004

23. Zych K, Perepelov AV, Baranowska A, Zabłotni A, Knirel YA, Sidorczyk Z (2005) Structure and serological studies of the O-polysaccharide of Proteus penneri 75 Epitopes and subgroups of Proteus serogroup O73. FEMS Immunol Med Microbiol 43:141-148. doi:10.1016/j.femsim.2004.07.011

24. Di Padova FE, Brade H, Barclay GR, Poxton IR, Liehl E, Schuetze E, Kocher HP, Ramsay G, Schreier MH, McClelland DB, Rietschel ET (1993) A broadly cross-protective monoclonal antibody binding to Escherichia coli and Salmonella lipopolysaccharides. Infect Immun 61:3863-3872 